\title{
The social Media Discourse Presidential Candidates: A Case Study of the 2018 Election in Cyprus
}

\author{
Professor Kostas Gouliamos \\ European University Cyprus \\ 6 Diogenes Street, Engomi, 1516 \\ Nicosia \\ Cyprus
}
Adjunct Professor Thodoros Roussopoulos
European University Cyprus
6 Diogenes Street, Engomi, 1516
Nicosia
Cyprus

\author{
Dr. Nasios Orinos \\ 6 Director, Cyprus College \\ Diogenes Street, Engomi, 1516, Nicosia \\ Cyprus \\ Athanasios Maimaris \\ Lecturer, Cyprus College \\ 6 Diogenes Street, Engomi, 1516, Nicosia \\ Cyprus
}

\begin{abstract}
Social Media is at the heart of all global communication intercourse. Moreover, they generate a novel political participation among voting population, particularly in the realm of young generation. This participation makes also western societies`citizens consider their input as an essential segment of the (post) modern democratic process. In light of this, the current American and French presidential campaigns have been adjusted to the ever-changing social media apparatus to address the diversifying voting population. The use of social media seems to be in an early stage in Cyprus, but still, during the 2018 Cyprus presidential elections along with traditional media, social media were part of the candidates' main communication strategy.
\end{abstract}

Keywords: Social Media, Facebook, Twitter

\section{Introduction}

Cyprus is a "Presidential Democracy" in which the importance of the President is enormous since it exercises executive power. There is, of course, the House of Representatives which cannot overthrow the President before his/her term expires. The President of the Republic is not only the Head of State but also the Head of the Government. The electoral system is fairly simple since it essentially applies the $50+1$ rule, meaning the country is considered as a single region and the candidate who gets $50 \%+1$ vote is elected president. If there are enough candidates and no one gets $50 \%+1$ in the first round, the two predominant candidates move to a second round. Presidential elections are held every 5 years, while the law does not impose a specific number of terms. It is noted that the presidential election is not a party election, that is, the party power is not measured, but it concerns the election of a person, the president. During the 2018 Cyprus Presidential Elections, Nicos Anastasiades, candidate of the right party and Stavros Malas, candidate of the left party, have been the two predominates who moved to the second round of the election. At the first round, Nicos Anastasiades finished first after receiving $35.51 \%$ (137,268 votes) of the valid votes and Stavros Malas finished second after receiving $30.24 \%(116,920)$ of the valid votes. At the second round, Nicos Anastasiades won the election with $56 \%$ of the valid votes. This paper portrays that the 2018 Cyprus Presidential election candidates have taken advantage of the conventional methods of political communications, but at the same time have used digital technology in their main communication strategy. The purpose of this study is to fully comprehend and explore the communicative techniques of social media and their implications as a conduit to maximize both, the political interest-engagement and 
the communication-information flow used by the two ending candidates of the presidential campaign 2018 in Cyprus. More specifically, the study aims to explore the following seven domains:

1. Media used and degree of usage of traditional ways versus social media

2. The percentage of voters using the social media

3. Whether the candidates have used social media as a political communication strategy tool and in what extent.

4. Candidates' strategic positioning in the social media, especially during the first and second round of the presidential election.

5. Nature of debates: TV versus other forms of debates and number of citizens watched the debates over the internet.

6. Whether the social media have acted as a reference guide in fostering a more active electorate, especially among the younger generation and in what extent.

The paper starts by citing a theoretical background explaining how the social media has influenced voting participation in the recent US and French presidential elections. Furthermore, the paper provides the methodology used in the study explaining in detail how the survey is organized, executed and analyzed. The last part of the paper presents the findings of the study ending with a discussion.

\section{Review of Literature}

Hughes (2018) highlights that social media is the latest and by far the most effective weapon of mass communication and it has been quickly adopted by political parties all around the world. According to Goldman (2013), each day, over 20 billion minutes are spent on Facebook. Not only is a high percentage of the world's population on Facebook, but over half of its registrants log onto the site at least once a day. In many cases, rather than beginning a web-browsing session with the static old media properties like The New York Times, people are using social networks as an entry point of sorts to the Internet. They will follow recommended content from Facebook or Twitter and then follow links off-site. Gottfried et al. 2016 (as cited by Curry 2018) note that with regard to the 2016 US Presidential Election, 44 percent of people utilized social media for political information, with men (47 percent) using it slightly more than women (41 percent). Safiullah et al. note that in the present era of electronic revolution when the social media has become the means and end of all communication even, political parties are also considering social media for their marketing and advertising purpose. As they say, Social Media has today become a very powerful tool for expressing opinions, views, and ideas and has become an influential tool of opinion creation. According to Luo \& Zhang, 2013 (as cited in Safiullah et al.), web 2.0 technologies provide web experience from the buzz. Social media Buzz is a term used in viral marketing and this can be defined as the interaction of people on social networking sites about product or service or an idea which amplifies or alters the unique marketing message. This emotion, excitement, energy, or anticipation about a product, service or an idea can be positive or negative. Prior 2007 (as cited by Curry 2018) argues that the media environment is a key consideration and the best predictor of voter turnout. He found that greater media choice has allowed greater opportunity to self-select out of exposure to news and political information, allowing entertainment choosers to avoid it altogether. The result is that those most interested in news and politics, who are more partisan by nature, turn out to vote, leading to polarization in our political system. There are differences between traditional media and social media as information sources. Bode and Dalrymple 2014, (as cited by Curry 2018) further note that Twitter users, for example, have been found to be more engaged in politics, have higher interest in politics, and trust traditional media less. At the same time Curry (2018) found that respondents 18-29 years old, the majority (51.6 percent) fall into the 'Prefers Social Media' group whereas Shearer and Gottfried 2017 (as cited by Curry 2018) note that men tend to use Twitter, YouTube and LinkedIn more. When it comes to campaigns, the main social media used are mainly Facebook, Twitter, YouTube and Instagram. Specifically, the battle is given in terms of likes on Facebook, followers on Twitter and Instagram and views on YouTube. Page and Duffy (2018)support that platforms like Facebook and Twitter expand the abilities of a campaign to engage directly with publics through daily and daylong posts and tweets, often accompanied by visual images. Bimber et al. (as cited in Bright et al, p.3) highlight that social media platforms such as Twitter have altered the 'media ecology' surrounding the public during political campaigns and these changes have opened up a variety of mechanisms through which a political candidate might influence voting outcomes. As they say, these are split into two basic types of pathway: direct and indirect mobilisation. In terms of direct mobilisation, it is possible that the use of Twitter might open a channel of direct communication between the political candidate in question and citizens who are eligible to vote. In addition to these direct connections, there is also the possibility of indirect mobilisation. Murthy (as cited by as cited in Bright et al, p.4) note that campaigning on platforms such as Twitter can be used to generate traditional press coverage, as the press themselves are covering social media, through a process sometimes described as inter-media agenda setting. This press coverage may then stimulate further interest on the part of voters whilst news articles may be shared via social media by either the candidate 
themselves or their supporters. According to Christodoulou (2018), Barack Obama was the first candidate on the planet who have used social media in the 2008 campaign.

His campaign message 'yes we can' flooded on Twitter and his speeches went on YouTube recording millions of views. Kessler (as cited in Page and Duffy 2018, p. 7) supports that in November 2008, Twitter had about four million users out of whom 100,000 followed candidate Obama. As of March 1 2012, President Obama had more than 12.5 million Twitter followers and, as Kessler argues, the popularity and influence of social media continues to accelerate, especially with young adults.

Research by Byers (as cited in Page and Duffy 2018, p. 7) indicates that $33 \%$ of adults younger than 30 years old got news from social networking sites, up from $12.5 \%$ in 2010, a $260 \%$ increase. Villanti et al (2016), have found that in $2014,89.42 \%$ of young adults reported regular use of at least one social media site. This increased to $97.5 \%$ of young adults in 2016. Among regular users of social media sites in 2016, the top five sites were Tumblr (85.5\%), Vine (84.7\%), Snapchat $(81.7 \%)$, Instagram (80.7\%), and LinkedIn (78.9\%). Respondents reported regularly using an average of 7.6 social media sites, with $85 \%$ using 6 or more sites regularly. Overall, $87 \%$ of young adults reported access or use of a smartphone with Internet access, $74 \%$ a desktop or laptop computer with Internet access, $41 \%$ a tablet with Internet access, 29\% a smart TV or video game console with Internet access, $11 \%$ a cell phone without Internet access, and 3\% none of these. According to Wong (2019), Trump is way ahead of the field. He has spent more than $\$ 11.1 \mathrm{~m}$ on Facebook and Google ads alone in the first six months of 2019. As Wong notes, for the corresponding six months of the most recent presidential race with an incumbent - January through June 2011, Barack Obama spent just $\$ 850,000$ on online advertising, according to Federal Election Commission (FEC) filings. Mike Schneider (as cited in Wong 2019) reveals that since Facebook began archiving political ads in May 2018, Trump has run about 26,000 that mention "fake news"; 14,000 that reference the border; and 3,600 that include the phrase "witch hunt". Jessica Alter, (as cited in Wong 2019), points out that Trump's campaign isn't incredibly sophisticated compared to corporations and how they use digital. It's just that politics is way behind. She adds that Trump spent $44 \%$ of his media budget on digital whereas other campaigns are closer to 6-8\%. Industry standard for corporations is 54\%. On the contrary, the use of Social Media seems to be in an early stage in Cyprus when it comes to elections. During the 2008 Cyprus presidential elections, Twitter was still unknown, only few had Facebook accounts, whereas YouTube was at an infant stage. Inevitably, the 2008 elections had used the traditional ways, mainly television, radio, newspapers and outdoor. It was in the 2013 presidential elections when things had started rolling in terms of social media. It was then that most candidates had incorporated Facebook into their campaigns. It was in the 2018 elections though that, social media were used on a full scale. All campaign staffs had fully incorporated social media into their general communication strategy and in general had a strong presence in social media, mainly on Facebook, Twitter and YouTube. The delay is not interpreted as a defeat of the new ways of political communication as much as a delay with which Cypriot society, and consequently the Cyprus Electorate, uses the "new" social media. Much of this delay is due to the fact that the population of the Republic is aged and the young who enter the electorate are proportionately much less than the old voters. According to the official data of the ministry of interior ${ }^{1}, 50 \%$ of the electorate, namely 272508 of 550693 voters, are aged 50+, while young people aged 18-29, who as a rule use digital technology more frequently, are only 92821 , or $17 \%$ of the electorate. It should be noted that the percentage of young people who usually abstain from elections is close to 50\%, which means that very few of them usually cast a vote. Christodoulou (2018), notes that just before the first round of the 2018 Cyprus presidential elections Nicos Anastasiades overcame Stavros Malas in all areas. It should be noted that Nicos Anastasiades had the advantage of transferring knowhow from the 2013 election. Specifically, he had 39911 likes on Facebook as opposed to 20450 of Stavros Malas. On Twitter, Nicos Anastasiades's dominance was complete. He counted 74000 followers, whereas Stavros Malas counted only 1436. Research conducted by 'Onisilos' Research Office (Markantonis 2018)shows that during the 2018 presidential elections TV was the primary means of information for the electorate with $70 \%$ of voters indeed being informed from TV, but with a significant $40 \%$ of them being informed from the internet. As Onisilos Research Office notes, the internet was mainly used as a means of receiving information by young people.

\section{Methodology}

\subsection{Research type and approach}

The study incorporates exploratory research via a qualitative approach. As Zikmund (2003) points out, exploratory research is conducted when research intends to gain a better understanding of the dimensions of a problem. Usually it provides greater understanding of a concept or crystallizes a problem rather than providing a precise measurement.

${ }^{1}$ Cyprus Ministry of Interior. (2018). Personal communication to authors 
Most exploratory research designs provide qualitative data that provide greater understanding of a concept. In accordance with the research objectives, the study followed two paths of action:

Part 1 gains insight to the problem through experience surveys, which is mainly the discussion of a concept with top executives and with knowledgeable people, in this case the social media experts. Specifically, as experts in the field the social media managers of both candidates were interviewed. In light of the above, secondary data analysis, mainly statistical background information was conducted. The two elements are synthesized in such a way that gives light on the survey's objectives. The above approach provides a coherent whole that is carefully designed and will lead to safe conclusions and recommendations. The approach has worked with key stakeholders and drawn on evidence from the appropriate sources all of whom are greatly affected by the election result.

\subsection{Sampling}

Three social media experts, one from each of the three main candidates, were interviewed, in an attempt to grasp an indepth perspective. Specifically, Maria Charalambous, Social Media Manager of Nicos Anastasiades's campaign staff, Demetris Demetriou, Social Media Manager of Stavros Malas' campaign staff and Pantelis Vladimirou, Social Media expert were interviewed. Based on the research objectives, the proposed sample size is enough to provide sufficient feedback and insight and ensure that safe conclusions are made.

\subsection{Gathering data}

Experience surveys were conducted face-to-face and took place at the respondents' location. Results were handwritten on unstructured questionnaires (transcripts) and analyzed during the analysis stage. This stage was tested for validity. Respondents were contacted by phone prior to the study for their permission and to be informed about the topic of interest. Each experience survey lasted for approximately 45 minutes.

\subsection{Analysis}

The method used to analyze the experience surveys followed four flows of action: data copying, data display, theme creation and conclusions and verification. Data were copied exactly as they were on transcripts so that they were more readily accessible and understandable, enabling the drawing out of various themes and patterns. Based on this process, various analytic conclusions were made. Data display intends to convey that data are presented as an organized, compressed assembly of information that permits conclusions to be analytically drawn. Emphasis was granted to the "Teaming" method. A diagram was used to aid understanding and to facilitate the ability to present major concepts. Teamed up were the most important ideas. This assisted the understanding and observation of certain patterns in the data. The conclusions drawn were confirmed to assure that they are real and not biased by the authors' thinking. For validity reasons another researcher independently examined the data and drew his own conclusions (face validity). Results were compared to ensure that conclusions were similar.

\subsection{Ethical Considerations}

Great emphasis was given to the ethical aspect of the study. As Zikmund (2003) points out, ethical issues in survey research are of primary importance. As he notes, the respondent's right to privacy, use of deception, the respondent's right to be informed about the purpose of the research, the need for confidentiality, the need for honesty and objectivity in collecting and reporting data, and other issues are factors in the design and execution of surveys. Along these lines, participants were specifically informed that taking part in the survey was voluntary and that in the case of refusal, no consequences would take place. On the other hand, it was explained to them that their participation was valuable because the findings would be taken into consideration, with a potential impact on the way elections are conducted in Cyprus.

\subsection{Epistemology}

This project is expected to have significant impact upon the political system in Cyprus. The way this project was approached sets the boundaries for fundamental changes in the way elections will be performed in the future. The project has worked with key stakeholders, all of whom they had a strong voice on the outcome. The work undertaken reflects closely the ideas and views of all stakeholders and is expected to greatly affect the outcome. We certainly believe that the approach used in this work has a valid epistemological grounding. The study falls under the umbrella of a case study that is injected with the views of experts and synthesized with secondary data analysis, that are appropriate for the problem under investigation. We have used the qualitative approach, incorporating secondary research and experience surveys. Special attention was given to the method of gathering data, but also to ethical considerations. Analysis involved a significant part of this project and involved a four flowed procedure. Lastly, the work done was approached with the greatest responsibility. Therefore, through the above approach used, we can count on the epistemology of this work and we can be certain that the results are valid.In addition, we strongly believe that voice of 
stakeholders will bring a great impact. By considering the social media as a perceptible discourse network of relations, our examination of the above domains will bring a broad base of knowledge to a research zone that requires further thoughts on the juxtaposition of political campaigns.

The work undertaken presents a new offer to all parties and future candidates to help further entrench a culture of learning, ensuring that future elections in Cyprus will follow a different, broader and more effective path.

\section{Analysis}

This section quotes the results as those were reported by three social media experts.

3.1 Media used and degree of usage of traditional ways versus social media

We need to mention that for both candidates' social media were used in parallel to traditional mediums. Pantelis Vladimirou, social media expert ${ }^{2}$, noted that mentions have been way more in traditional media than in social media. As he explained, 'mentions' show volume whereas 'engagement' shows reaction and of course engagements are stronger than just volume. Numbers prove though that the use of social media has increased compared to previous elections. Maria Charalambous ${ }^{3}$, notes that Nicos Anastasiades has mainly used Facebook, Twitter and Instagram. All three media have been heavily used with everyday messages from October 2017 to February 2018 on a 24-hour basis. Especially, during the last three months of the campaign, from November of 2017 to January of 2018, Nicos Anastasiades had a total of 20,000,000 impressions on all media together and a total of 2,300,000 video views. Engagement reached 358000 voters, out of which 311000 were likes and 17000 were comments on different posts, while his campaign received 685000 clicks on posts. According to Demetris Demetriou ${ }^{4}$, Stavros Malas has also used YouTube besides Facebook, Twitter and Instagram. All media have been heavily used in the campaign also from August 2017 to February 2018 on a 24-hour basis. When Stavros Malas run for president again back in 2013, Facebook likes had stopped at 10,000, increasing to 23000 in February of 2018. Furthermore, Stavros Malas had just 250 Twitter followers in 2013, going up to 2000 followers in 2018. On September of 2017 Stavros Malas had zero followers on Instagram, finishing at 1560 in February of 2018, whereas YouTube views were again at zero in September of 2017 finishing at 46500 views and 150 subscribers. Pantelis Vladimirou, highlighted the importance of engagements. He noted that if we were to distinguish the social media, we could easily spot that mentions are a lot more in Twitter because its fans are more active and, in some instances, they twitted dozens of messages in a day. The volume of mentions during elections is recorded in Table 1:

Table 1. Volume of mentions during 2018 presidential elections in Cyprus

\begin{tabular}{ll}
\hline Percentage & Social Media \\
\hline 58 & Twitter \\
25 & Online news \\
10 & Blogs \\
7 & Facebook \\
\hline
\end{tabular}

Things though are different when it comes to engagements, like shares, likes and comments. Facebook has been way stronger in engagements compared to other media and it seems that Nicos Anastasiades has been way stronger in Facebook compared to Stavros Malas. Engagements during elections are recorded in Table 2:

\section{Table 2. Engagements during 2018 presidential elections in Cyprus}

\begin{tabular}{ll}
\hline Percentage & Social Media \\
\hline 75 & Facebook \\
10 & Online news \\
11 & Twitter \\
4 & Blogs \\
\hline
\end{tabular}

\subsection{Percentage of voters using social media}

According to Demetris Demetriou, 500,000 voters in Cyprus have a Facebook account, consequently meaning that pretty much the whole electorate uses Facebook. Out of those, around 300,000 are Greek speaking. Stavros Malas' campaign targeted around 300,000 voters through Facebook. Nicos Anastasiades's reached a total of 500,000 voters through social media, a number way higher than that of his opponent.

\footnotetext{
${ }^{2}$ personal communication via email to authors, March 23, 2018

3 personal communication via email to authors, March 15, 2018

${ }^{4}$ personal communication via email to authors, March 7, 2018 
3.3 Whether the candidates have used social media as a political communication strategy tool and in what extent

Both candidates have used social media as a strategic communication tool. Nicos Anastasiades and Stavros Malas had communication plans specifically designed for reaching the social media on an everyday basis.

Message results were evaluated every day. Through Instagram Stavros Malas targeted voters aged 18-35 mainly through short messages and hashtags. YouTube was used for uploading videos and in cooperation with websites videos were forwarded on the websites for people to see. Twitter was used for quick messaging and Facebook was heavily used for targeted advertising through specific messages.

3.4 Candidates' strategic positioning in the social media, especially during the first and second round of the presidential election

During the elections Nicos Anastasiades's strategic positioning was to promote the work that the government has accomplished during his first term in the presidency. All positioning activities in both rounds targeted to let voters know what has been accomplished on three main pillars: Economy, the Cyprus problem and the president's European presence and in general his International relations. In contrast, Stavros Malas has followed a defensive positioning. In both rounds of the election he positioned himself as a 'mild' candidate who respected both the voters as well as other candidates. He tried to reach the electorate with words like 'hope' and 'change'.

3.5 Nature of debates: Tv versus other forms of debates and number of citizens watched the debates over the internet

There have been only two debates during the election campaign which both took place on TV. The 1st debate took place a few days just before the 1st round of the elections, specifically on the 22nd of January 2018 and in which all five candidates participated. The 2nd debate which took place on the 31st of January 2018, a few days before the second round of the election between the two predominant contenders had followed a different approach compared to the 1st one. While the 1st debate followed the 'monologue' approach during which candidates were given a specific amount of time to answer a question, the 2nd debate followed the so called 'French' model based on which a question was posed, and candidates were left up to an open discussion. The 1 st debate had reached 24300 voters through Facebook and had 9512 views while the 2nd one had reached almost two times those numbers. Specifically, it reached 40,000 voters through Facebook and had 17000 views. In addition, the second debate had around 4100 total tweets, out of which 1963 were tweet hashtags, 1402 were tweets concerning Stavros Malas and 719 were tweets concerning Nicos Anastasiades. As far as TV is concerned, based on data from Nielsen Audience Measurement Cyprus ${ }^{5}$, debates had viewership as in Table 3:

Table 3. Debate viewership during 2018 presidential elections in Cyprus

\begin{tabular}{lllll} 
& \multicolumn{2}{c}{$1^{\text {st }}$ debate } & \multicolumn{2}{c}{$2^{\text {nd }}$ debate } \\
\hline TV Channel & Voters & Share & Voters & Share \\
\hline RIK & 70616 & $19.7 \%$ & 83169 & $23.9 \%$ \\
TVONE & 40032 & $11.1 \%$ & 42512 & $12.2 \%$ \\
ANT1 & 34092 & $9.5 \%$ & 32322 & $9.3 \%$ \\
SIGMA & 51429 & $14.3 \%$ & 63894 & $18.4 \%$ \\
ALPHA CYPRUS & 21972 & $6.1 \%$ & 28140 & $8.1 \%$ \\
\hline
\end{tabular}

The viewing behavior variables include:

- Average Minute Rating (AMR)= average number of voters who watched the debate per minute, aged 18+

- Share percentage $($ SHR\%) = percentage on all who were watching TV at the time of the debate

Numbers show that indeed the 2 nd debate was viewed by a larger number of voters compared to the 1 st debate.

3.6 Whether the social media have acted as a reference guide in fostering a more active electorate, especially among the younger generation and in what extent.

Indeed, the social media were used for fostering the younger generation. Both candidates went out with specific actions to reach younger voters. For example, Stavros Malas main action was the use of a video that was uploaded on a website (“Т $\alpha \Sigma \kappa \alpha \lambda \iota \omega ́ \tau \iota \kappa \alpha '$ [Ta Skaliotika]" 2018), owned by two stand-up comedians and it attracts people aged 18-24. The video was successful and had more than 70000 views. Demetris Demetriou, has noted that he does not really believe they have shaken things up because it seems there is no much interest in younger people. Certainly thought, he believes that things are way better today than they were in 2013, during which similar videos had only 500 views. It seems that gradually the social media is reaching people.

${ }^{5}$ Nielsen Audience Measurement Cyprus. (2018). Personal communication to authors 
On the other hand, Maria Charalambous, notes that young people have distanced themselves from traditional media, while they are everyday users of the internet and social media. Based on this it seems that indeed social media have acted as a reference guide in fostering a more active electorate, especially among the younger generation.

\section{Discussion}

The authors' original hypothesis that during the 2018 Presidential Elections social media were used supportively is proven wrong. The findings of the study point out that for both candidates' social media were used in parallel to traditional mediums and that campaign staffs have used social media in their main communication strategy. In addition, both candidates have used social media as a strategic communication tool through which they positioned themselves accordingly.

Furthermore, a large number of voters was reached through social media, whereas, while budget spend for traditional mediums was still way higher than the one spent on social media, budget for social media was higher compared to previous elections. Lastly, indeed the social media were used for fostering the younger generation as it seems that gradually is reaching people. It seems that young people have distanced themselves from traditional media, while they are everyday users of the internet and social media. The literature notes that social media has been used in US and France long before, on the contrary during the 2008 Cyprus Presidential Elections social media was still unknown, whereas it was in the 2018 elections that social media were used on a full scale. Furthermore, voting participation in the recent US and French presidential elections were largely influenced by social media, a trend that is gradually reaching Cyprus as well. As the numbers prove, the use of social media has increased compared to previous elections. Experts suggest that indeed social media have acted as a reference guide in fostering a more active electorate in Cyprus, especially among the younger generation. In addition, the literature suggests that when it comes to campaigns, the main social media used are Facebook, Twitter, YouTube and Instagram a trend that exists for Cyprus as well. The heavy use of social media during elections seems to offer important merits to candidates. Just like Barack Obama in 2008, Nicos Anastasiades's stronger use of social media in 2018 gave him the election race.

\section{Conclusion}

In the above content, it appears that the use of social media in Cyprus follows an increasing trend while social media seem to influence turnout especially in younger people. Facebook, Twitter, YouTube and Instagram are the main mediums used and money spent on these media is gradually increasing. Despite the significant steps, a room for improvement lies ahead. The challenge that lies before us as a country is to strive and find ways to increase social media usage furthermore.

\section{Bibliography}

Andrew Hughes. 2018. 'Weapons of Mass Consumption: Social and Digital Media in Political Campaigns'. Market Driven Political Advertising : Social, Digital and Mobile Marketing. :61-78

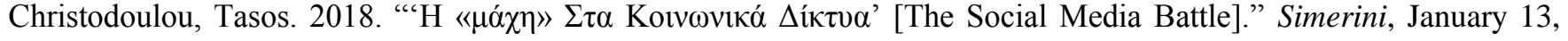
2018.

Goldman, Jeremy. 2013. 'Going Social : Excite Customers, Generate Buzz, and Energize Your Brand with the Power of Social Media'. New York: AMACOM. 2013. eBoo

Jonathan Bright, Scott Hale, Bharath Ganesh, Andrew Bulovsky, Helen Margetts, Phil Howard. 'Does Campaigning on Social Media Make a Difference? Evidence from candidate use of Twitter during the 2015 and 2017 UK Elections'.

Julia Carrie Wong. 2019. 'Way ahead of the field': inside the Trump's unprecedented social media campaign'. The Guardian. July 3, 2019.

Kevin Everett Curry. 2018. 'Politics in the Social Media Era: The Relationship Between Social Media Use and Political Participation During the 2016 United States Presidential Election'. Portland State University, ProQuest.

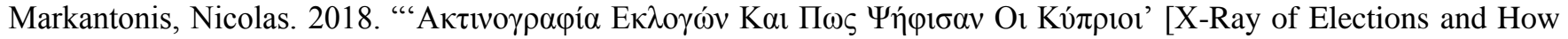
the Cypriots Voted]." Sigmalive, March 19, 2018.

Md Safiullah ,Pramod Pathak, Saumya Singh, AnkitaAnshul. 2016. 'Social media as an upcoming tool for political marketing effectiveness'. Asia Pacific Management Review. March 2017 22(1):10-15. http://eds.b.ebscohost.com/eds/pdfviewer/pdfviewer?vid=11\&sid=b2a0fefa-ccfa-4cbe-bb37fcfc98cc5dc1\%40sessionmgr101

Page, Janis Teruggi, and Margaret E Duffy. 2018. "What Does Credibility Look like? Tweets and Walls in U.S. Presidential Candidates' Visual Storytelling." Journal of Political Marketing 17 (1): 3-31. https://doi.org/10.1080/15377857.2016.1171819. 
Villanti AC, Johnson AL, Ilakkuvan V, Jacobs MA, Graham AL, Rath JM. 2016. 'Social Media Use and Access to Digital Technology in US Young Adults in 2016'. Journal Of Medical Internet Research, 1438-8871, 2017 Jun 07, Vol. 19, Issue 6. http://eds.b.ebscohost.com/eds/detail/detail?vid=7\&sid=b2a0fefa-ccfa-4cbe-bb37fcfc98cc5dc1\%40sessionmgr101\&bdata=JnNpdGU9ZWRzLWxpdmU\%3d\#AN=28592394\&db=mdc

Zikmund, William G. 2003. Exploring Marketing Research. 8th ed. Ohio: South-Western College Pub.

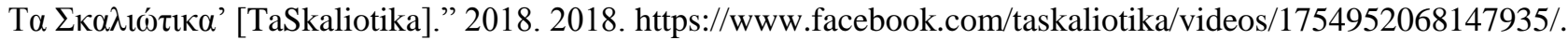

